\title{
Analisis Customer Satisfaction Pada Pengguna Platform Digital Shopee
}

\author{
Robby Andika Kusumajaya ${ }^{1)}$, Edwin Zusrony ${ }^{2)}$ \\ ${ }^{1,2}$ Manajemen Informatika, Sekolah Tinggi Elektronika dan Komputer \\ Jl. Majapahit No. 605, Pedurungan Semarang, Indonesia \\ Email: ${ }^{1}$ mr.robbyandika@gmail.com, ${ }^{2}$ dwwin.zusrony@gmail.com
}

\begin{abstract}
Abstrak
Aplikasi belanja online atau e-commerce menjadi sarana baru bagi masyarakat dalam gaya hidup berbelanja dengan media internet sebagai perantaranya. Kepuasan pelanggan dalam berbelanja secara elektronik amatlah diperhatikan oleh toko online untuk memberikan kenyamanan dan keamanan. Penelitian dilakukan untuk menganalisis pengaruh variabel information quality, financial security dan system quality terhadap variabel customer satisfaction pada pengguna paltform digital Shopee dengan melibatkan 100 responden mahasiswa jurusan komputer di kota Salatiga. Teknik sampling menggunakan purposive sampling method dan dianalisis menggunakan metode regresi linier berganda yang diolah menggunakan software SPSS 22. Hasil penelitian menunjukkan keseluruhan independent variable memiliki pengaruh signifikan terhadap dependent variable dengan nilai signifikansi kurang dari 0,05 . Hasil penelitian ini dapat menjadi saran kebijakan bagi perusahaan dalam meningkatkan pelayanan untuk mewujudkan kepuasan pelanggan.
\end{abstract}

Kata kunci:customer satisfaction, e-commerce, shopee

\section{PENDAHULUAN}

Perkembangan dunia digital yang digawangi oleh berbagai konten aplikasi berbasis online secara tidak langsung mengubah perilaku manusia dalam berbagi sendi kehidupan. Media sosial menjadi kebutuhan primer yang tidak dapat dipisahkan dari kehidupan msyarakat urban saat ini. Sentuhan gawai sebagai perangkat teknologi informasi membantu manusia untuk terhubung dengan dunia luar tanpa mengenal batas tempat dan waktu.

Salah satu perubahan yang beberapa tahun terakhir terasa adalah perilaku masyarakat dalam melakukan pembelian barang, dimana marak sekali dalam melakukan transaksi perdagangan melalui aplikasi online. Hal ini terlihat berdasarkan banyaknya jumlah pemakai aplikasi internet di negara Indonesia yang hampir mencapai 84 juta atau $30 \%$ dari total populasi penduduk. Pergeseran perilaku pembelian masyarakat diakibatkan oleh aspek kemudahan dan harga yang terjangkau (Prayoga, Priyadi and Dharmoputro, 2016).

Di Indonesia banyak sekali situs perdagangan online atau platform digital yang menawarkan produk-produknya dengan berbagai pilihan dan segmen konsumen. Perdagangan elektronik atau sering disebut $e$ commerce yang paling banyak digunakan adalah jenis $\mathrm{C} 2 \mathrm{C}$ (customer to customer), yang menghubungkan antara penjual dan pembeli yang difasilitasi oleh toko online sebagai penghubung.

Aplikasi e-commerce yang paling sering digunakan dalam bertransaksi di Indonesia adalah Shopee, hal ini dibuktikan oleh hasil survei dari iPrice Group pada tahun 2018 yang menobatkan Shopee sebagai aplikasi e-commerce peringkat pertama di Indonesia dan aplikasi shopee sudah diunduh kurang lebih 74 juta (Karina, 2019).

Dalam penelitian (Karina, 2019), yang mengukur kepuasan pelanggan pada aplikasi online Shopee menggunakan elemen-elemen e-servicescape, dimana hasilnya menunjukkan bahwa e-servicescape memiliki pengaruh kepada kepuasan pelanggan dan perceived value serta pada aspek functionality dan layout masih memerlukan beberapa perbaikan. 


\section{METODE PENELITIAN}

a. Desain Penelitian

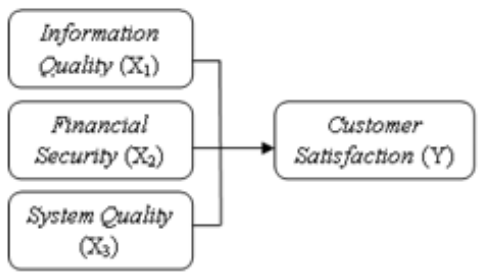

Gambar 1. Desain Penelitian

\section{b. Tahapan Penelitian}

Tahapan penelitian dijelaskan pada gambar 2 .

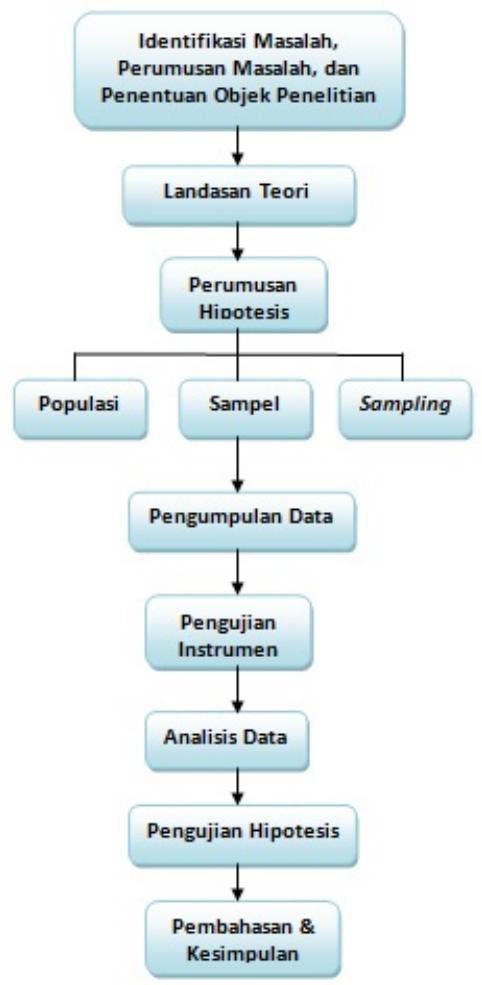

Gambar 2. Tahapan Penelitian

\section{c. Metode Pengumpulan Data}

Dalam proses pengumpulan data metode yang digunakan dengan menyebarkan kuesioner sebagai instrumen penelitian kepada responden yang terpilih.

Untuk pengukuran data yang didapat dari pengisian kuesioner digunakan skala Likert dari skala 1 sampai dengan 5 (dari Sangat Puas sampai dengan Sangat Tidak Puas).

\section{d. Populasi, Sampel dan Teknik Sampling}

Penelitian ini memiliki objek responden mahasiswa jurusan komputer di kota Salatiga.
Pengambilan sampel menggunakan teknik non probability sampling dengan metode purposive sampling, dengan pertimbangan kemudahan dalam mendapatkan data dan informasi. Jumlah sampel penelitian ini sebanyak 100 orang mahasiswa dengan memberikan kuesioner serta petunjuk pengsisiannya.

\section{TINJAUAN PUSTAKA \\ a. E-Commerce}

E-commerce merupakan salah satu upaya dari perusahaan untuk mencoba memasarkan dan menjual produk dan layanan serta membangun hubungan dengan pelanggan melalui media internet (Kotler and Armstrong, 2013).

E-commerce juga mengacu pada proses terjadinya transaksi bisnis atau kegiatan manajerial menggunakan media internet, dimana saat ini dengan e-commerce juga disederhanakan interaksinya dalam bentuk website (Sharma and Lijuan, 2015).

\section{b. Information Quality}

Information Quality adalah konten yang berisi berbagai komentar atau ulasan terkait karakteristik informasi dan perspektif oleh para pengguna atau konsumen (Park, D.-H., Lee, J., \& Han, 2007). Variabel Information Quality sangat mempengaruhi minat beli konsumen, dimana informasi yang memiliki kualitas lebih tinggi akan membuat konsumen merasa lebih puas serta memberika ulasan yang bagus (Filieri, McLeay and Tsui, 2017).

\section{c. Financial Security}

Financial Security merupakan salah satu aspek yang dominan dalam kepuasan konsumen didalam berbelanja secara online serta memiliki efek yang besar pada kepercayaan pelanggan (Ali et al., 2017).

Konsumen selalu memiliki rasa khawatir dengan kemungkinan dapat diaksesnya data keuangan (debit card atau credit card) oleh pihak ketiga. Penyedia jasa e-commerce yang bisa memberikan jaminan keaamanan finansial pada pelanggan maka akan meningkatkan kepercayaan dan kepuasan pelanggan. 


\section{d. System Quality}

System Quality adalah menunjukkan kinerja dari sistem informasi dalam aspek kenyamanan, keandalan, fungsionalitas, kemudahan penggunaan dan metrik sistem lainnya (Filieri, McLeay and Tsui, 2017).

Konsumen akan merasa senang serta puas apabila pada sistem aplikasi e-commerce mereka dapat dengan mudah dan cepat menemukan berbagai jenis informasi yang mereka butuhkan.

\section{e. Customer Satisfaction}

Customer Satisfaction adalah suatu ukuran berdasarkan evaluasi pelanggan baik berupa afektif maupun kognitif yang berdasar pada pengalaman pribadi dalam penerimaan sebuah kualitas pelayanan (Rahadi, 2011).

Customer Satisfaction juga dapat didefinisikan sebagai perasaan gembira atau tidak puas seseorang yang timbul setelah melakukan proses perbandingan antara hasil kerja atau produk dengan keinginan atau ekspektasi yang diharapkan (Kotler, 2012).

\section{HASIL DAN PEMBAHASAN}

Data diolah dari hasil survei menggunakan kuesioner kepada responden adalah sebagai berikut :

\section{a. Deskripsi Responden}

Tabel 1. Deskripsi Responden (Gender)

\begin{tabular}{|c|c|c|c|}
\hline \multicolumn{3}{|c|}{ Jenis } & \multirow[b]{2}{*}{ Presentase } \\
\hline No & Kelamin & Jumlah & \\
\hline 1 & Laki-laki & 29 & $29 \%$ \\
\hline 2 & Perempuan & 71 & $71 \%$ \\
\hline & Jumlah & 100 & $100 \%$ \\
\hline
\end{tabular}

Pada tabel 1, diketahui sebanyak $71 \%$ responden didominasi oleh jenis kelamin perempuan dan sisanya sebanyak $29 \%$ adalah responden dari jenis kelamin laki-laki.

Tabel 2. Deskripsi Responden (Usia)

\begin{tabular}{|c|c|c|c|}
\hline \multicolumn{3}{|c|}{ Kelompok } & \multirow[b]{2}{*}{ Presentase } \\
\hline No & Usia & Jumlah & \\
\hline 1 & $18-23$ & 83 & $83 \%$ \\
\hline 2 & $>23$ & 17 & $17 \%$ \\
\hline & Jumlah & 100 & $100 \%$ \\
\hline
\end{tabular}

Pada tabel 2, diketahui sebanyak $83 \%$ responden didominasi oleh usia 18-23 tahun dan $30 \%$ adalah responden dengan usia diatas 23 tahun.

\begin{tabular}{cccc}
\multicolumn{4}{c}{ Tabel 3. Deskripsi Responden (Progdi) } \\
\hline \multicolumn{3}{c}{ Program } \\
No & Studi & Jumlah & Presentase \\
\hline \multirow{3}{*}{1} & $\begin{array}{c}\text { Teknik } \\
\text { informatika } \\
\text { Sistem }\end{array}$ & 57 & $57 \%$ \\
2 & Informasi & 43 & $43 \%$ \\
\hline & Jumlah & 100 & $100 \%$ \\
\hline
\end{tabular}

Pada tabel 3, diketahui sebanyak 57\% responden didominasi oleh program studi Teknik Informatika dan sisanya $43 \%$ adalah responden dari program studi Sistem Informasi.

Tabel 4. Deskripsi Responden (Lama Penggunaan)

\begin{tabular}{|c|c|c|c|}
\hline \multicolumn{4}{|c|}{ Lama } \\
\hline No & Penggunaan & Jumlah & Presentase \\
\hline 1 & $<1$ Tahun & 25 & $25 \%$ \\
\hline 2 & $>1$ Tahun & 75 & $75 \%$ \\
\hline & Jumlah & 100 & $100 \%$ \\
\hline
\end{tabular}

Pada tabel 4, diketahui sebanyak $75 \%$ responden didominasi oleh pengguna yang sudah lebih dari 1 tahun dan sisanya $25 \%$ adalah pengguna yang pemakaiannya kurang dari 1 tahun.

\section{b. Uji Validitas}

Pengujian ini dipergunakan untuk mengukur sah atau tidaknya hasil dari pengisian kuesioner (Ghozali, 2016). Berdasarkan hasil pengujian korelasi product moment pada butir-butir pertanyaan dalam angket untuk variabel Information Quality $\left(\mathrm{X}_{1}\right)$, Financial Security $\left(\mathrm{X}_{2}\right)$, dan System Quality $\left(\mathrm{X}_{3}\right)$ memiliki nilai positif dimana nilai signifikansi r-hitung lebih besar dari rtabel, dimana semuanya diatas 0,195 (nilai $r$ tabel).

\section{c. Uji Reliabilitas}

Uji reliabilitas merupakan sebuah alat untuk melakukan pengukuran pada kuesioner yang merupakan konstruk (Ghozali, 2016). Hasil uji reliabilitas dapat dilihat dari nilai Cronbach's Alpha dari variabel Information Quality $\left(\mathrm{X}_{1}\right)$, Financial Security $\left(\mathrm{X}_{2}\right)$, dan System Quality $\left(\mathrm{X}_{3}\right)$ yang lebih dari 0,6 
(critical value) dan disimpulkan hasilnya semua variabel dinyatakan reliabel.

\section{d. Uji Hipotesis}

H1 : Information Quality memberi pengaruh positif serta signifikan terhadap Customer Satisfaction

$\mathrm{H} 2$ : Financial Security memberi pengaruh positif serta signifikan terhadap Customer Satisfaction

H3 : System Quality memberi pengaruh positif serta signifikan terhadap Customer Satisfaction

\section{e. Analisis Regresi Linier Berganda}

Tabel 5. Hasil Regresi Linear Berganda

\begin{tabular}{|c|c|c|c|c|}
\hline $\begin{array}{c}\text { Variab } \\
\text { el }\end{array}$ & $\mathbf{B}$ & $\begin{array}{c}\mathbf{t}- \\
\text { hit. }\end{array}$ & Sig & Hasil \\
\hline Const & 4,243 & & & \\
\hline $\boldsymbol{X 1}$ & 0,495 & $\begin{array}{c}7,65 \\
4\end{array}$ & $\begin{array}{c}0,00 \\
0\end{array}$ & Sig, H1 diterima \\
\hline $\boldsymbol{X} \mathbf{2}$ & 0,125 & $\begin{array}{c}2,07 \\
6\end{array}$ & $\begin{array}{c}0,04 \\
1\end{array}$ & Sig, H2 diterima \\
\hline $\boldsymbol{X} \mathbf{3}$ & 0,163 & $\begin{array}{c}3,29 \\
4\end{array}$ & $\begin{array}{c}0,00 \\
1\end{array}$ & $\mathrm{Sig}, \mathrm{H} 3$ diterima \\
\hline $\begin{array}{l}\text { Rsquar } \\
\boldsymbol{e}\end{array}$ & 0,521 & \multicolumn{5}{|c|}{$\begin{array}{c}X_{1}, X_{2} \text { dan } X_{3} \text { secara simultan } \\
\text { berpengaruh terhadap variabel Y } \\
\text { (Customer Satisfaction) }\end{array}$} \\
$\begin{array}{l}\boldsymbol{F} \text { - } \\
\text { hitung } \\
\text { Sig. } \boldsymbol{F} \text { - } \\
\text { hit }\end{array}$ & 34,855 & $0,000 \mathrm{a}$ & \multicolumn{5}{|c}{} \\
\hline
\end{tabular}

Pada tabel 5. Nilai F-hitung 34,855 lebih besar dibandingkan dengan F-tabel sebesar 2,68 dengan nilai signifikansi sebesar 0,000a yang lebih kecil dari 0,05 , dimana dijelaskan bahwa variabel Information Quality $\left(\mathrm{X}_{1}\right)$, Financial Security $\left(\mathrm{X}_{2}\right)$, dan System Quality $\left(\mathrm{X}_{3}\right)$ secara silmutan memiliki pengaruh terhadap variabel Customer Satisfaction.

Nilai yang diperoleh dari uji koefisien determinasi yaitu nilai Adjusted $R$-Square 0,506 . Nilai mencerminkan terdapat variasi independent variable yang ditunjukkan dengan jumlah presentase $52,1 \%$ dalam menjelaskan variabel dependen (terikat), lalu sisanya dijelaskan komponen lain diluar model penelitian sebesar $47,9 \%$.

Persamaan model regresi liner berganda dapat dijabarkan sebagai berikut : $\mathrm{Y}=4,243+0,495 \mathrm{X}_{1}+0,125 \mathrm{X}_{2}+0,163 \mathrm{X}_{3}+\mathrm{e}$

\section{f. Uji t}

1). Pengaruh Information Quality $\left(\mathrm{X}_{1}\right)$ terhadap Customer Satisfaction (Y)

Hasil nilai Information Quality untuk thitung 7,654 $(\mathrm{df}=1,960)$ dengan Sig. 0,000< 0,05 , mengindikasikan Information Quality memberi pengaruh positif serta signifikan atas Customer Satisfaction ( $\mathrm{H}_{1}$ diterima). Semakin meningkatnya nilai Information Quality maka tingkat Customer Satisfaction akan semakin meningkat pula.

\section{2). Pengaruh Financial Security $\left(\mathrm{X}_{2}\right)$ terhadap Customer Satisfaction (Y)}

Hasil nilai Financial Security untuk thitung 2,754 (df=1,960) dengan Sig. 0,041< 0,05, mengindikasikan Financial Security memberi pengaruh positif serta signifikan atas Customer Satisfaction $\left(\mathrm{H}_{2}\right.$ diterima). Semakin meningkatnya nilai Financial Security maka tingkat Customer Satisfaction akan semakin meningkat pula.

\section{3). Pengaruh System Quality $\left(\mathrm{X}_{3}\right)$ terhadap Customer Satisfaction (Y)}

Hasil nilai System Quality untuk thitung 3,294 (df=1,960) dengan Sig. 0,001 < 0,05, mengindikasikan System Quality memberi pengaruh positif serta signifikan atas Customer Satisfaction ( $\mathrm{H}_{3}$ diterima). Semakin meningkatnya nilai System Quality maka tingkat Customer Satisfaction akan semakin meningkat pula

\section{KESIMPULAN DAN SARAN}

\section{a. Kesimpulan}

Berdasarkan hasil riset yang dilakukan dapat disimpulkan bahwa variabel information quality, financial security dan system quality berpengaruh secara positif dan signifikan terhadap variabel customer satisfaction pada pengguna aplikasi $e$ commerce Shopee di kota Salatiga. Berdasarkan uji hipotesis dapat dibuktikan pada setiap variabel independen memberikan hubungan secara positif terhadap variabel dependen yaitu customer satisfaction.

\section{b. Saran}

Hasil penelitian diharapkan dapat dijadikan saran kebijakan bagi perusahaan untuk selalu meningkatkan pelayanan kepada 
para pelanggan dengan senantiasa menghadirkan inovasi-inovasi terbaru.

\section{REFERENSI}

Ali, N. I. et al. (2017) 'Online shopping satisfaction in Malaysia: A framework for security, trust and cybercrime', in Proceedings - 6th International Conference on Information and Communication Technology for the Muslim World, ICT4M 2016, pp. 194198. doi: 10.1109/ICT4M.2016.43.

Filieri, R., McLeay, F. and Tsui, B. (2017) 'Antecedents of Travellers' Satisfaction and Purchase Intention from Social Commerce Websites', in Information and Communication Technologies in Tourism 2017, pp. 517-528. doi: 10.1007/978-3-319-51168-9 37.

Ghozali, I. (2016) Aplikasi Analisis Multivariete Dengan Program IBM SPSS 23 (Edisi 8). Cetakan ke VIII, Penelitian. doi: 10.1021/ol7029646.

Karina, M. (2019) 'Pengaruh E-servicescape Online Marketplace Shopee pada Perceived Value dan Kepuasan Pelanggan, serta Dampaknya terhadap Loyalitas Pelanggan', Jurnal Maksipreneur, $\quad 9(1) . \quad$ doi: 10.24912/jmbk.v3i1.4917.

Kotler, P. (2012) Marketing management/Philip Kotler, Kevin Lane Keller, Marketing management.

Kotler, P. and Armstrong, G. (2013) Principles of Marketing 15th Global Edition, Pearson Education Limited. Available at: https://www.bookdepository.com/Princi ples-Marketing-Global-Edition-DrPhilip-T-

Kotler/9781292220178\%0Ahttps://boo ks.google.com/books?id=TahuAwAAQ BAJ\&pgis $=1$.

Park, D.-H., Lee, J., \& Han, I. (2007) 'The Effect of On-Line Consumer Reviews on Consumer Purchasing Intention: The Moderating Role of Involvement. International Journal of Electronic Commerce', Economic Management Journal, 11(4), pp. 125-148.

Prayoga, A. F., Priyadi, Y. and Dharmoputro, S. (2016) 'Pengaruh fitur chatting dan tawar pada aplikasi Shopee terhadap kepuasa pelanggan', e-Proceeding of Management, 3(3), pp. 2968-2975.

Rahadi, D. R. (2011) 'Pengaruh Karateristik Website Terhadap Kepuasan Pelanggan', Jurnal Teknologi Informasi Politeknik Telkom, 1(1), pp. 20-25.

Sharma, G. and Lijuan, W. (2015) 'The effects of online service quality of ecommerce Websites on user satisfaction', Electronic Library, 33(3), pp. 468-485. doi: 10.1108/EL-10-20130193. 